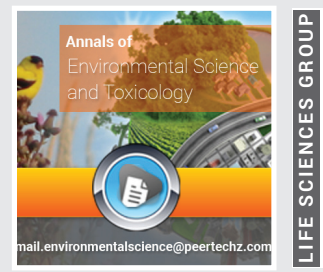

Luigi Mita ${ }^{1,2}$, Maurizio Forte ${ }^{1,2}$, Adriana Rossi ${ }^{2,3}$, Claudia Adamo ${ }^{2,3}$, Sergio Rossi ${ }^{2}$, Damiano Gustavo Mita ${ }^{1,2^{\star}}$, Marco Guida ${ }^{1,3}$, Marianna Portaccio ${ }^{4}$, Tzonka Godievargova ${ }^{5}$, Ivanov Yavour ${ }^{5}$, Mohamed Samir and Mohy Eldin ${ }^{6,7}$

\author{
'Institute of Genetics and Biophysics of CNR - \\ Naples - Italy \\ ${ }^{2}$ National Laboratory on Endocrine Disruptors of \\ INBB - Naples - Italy \\ ${ }^{3}$ Department of Biology - University Federico II - \\ Naples Italy \\ ${ }^{4}$ Department of Experimental Medicine - Università \\ degli Studi della Campania "Luigi Vanvitelli" \\ ${ }^{5}$ Department of Biotechnology - Prof. Assen Zlatarov \\ University - Burgas - Bulgaria \\ ${ }^{6}$ Polymer Materials Research Department, Advanced \\ Technology and New Materials Research Institute, \\ MuCSAT, Alexandria, Egypt \\ ${ }^{7}$ Chemistry Department, Faculty of Science, \\ University of Jeddah, Saudi Arabia
}

Dates: Received: 18 March, 2017; Accepted: 05 April 2017; Published: 07 April, 2017

*Corresponding author: Damiano Gustavo Mita , Institute of Genetics and Biophysics of CNR ,Via Pietro Castellino 11180131 - Naples - Italy, E-mail: gustavo.mita@igb.cnr.it

Keywords: 17a- Ethinylestradiol Removal; Adsorption; PAN beads; Kinetics; Isotherm diffusion; Models; Batch Reactors

https://www.peertechz.com

\author{
Research Article
}

Removal of 17- $\alpha$ Ethinylestradiol from Water Systems by Adsorption on Polyacrylonitrile Beads: Isotherm and

\section{Kinetics Studies}

\section{Abstract}

An investigation on the removal of 17-a-Ethinyl Estradiol (EE2) from aqueous solutions using Polyacrylonitrile (PAN) beads has been carried out under closed conditions. The kinetic and equilibrium results obtained for EE sorption with different initial concentrations have been analyzed. Experimental data at equilibrium have been correlated with the Langmuir, Freundlich, Tempkin, and Dubinin-Radushkevich $(D-R)$ isotherm models. The applicability of the isotherm equations to the adsorption system has been compared by means of the correlation coefficients. The adsorption data resulted fitted well by the Freundlich isotherm model. Kinetic analysis was performed with three different types of kinetic adsorption models using the pseudo-first-order, pseudo-second-order, and simple Elovich models. Analysis of the kinetic data indicated that the EE2 adsorption was a second-order process. Diffusion mechanisms have been analyzed by means of the diffusion rate equations inside particulate of Dumwald-Wagner and intraparticle models. The actual rate-controlling step involved in the EE sorption process was determined by further analysis of the sorption data by the kinetic expression given by Boyd. All together these results allowed to understand the adsorption mechanism of the process and have shown the usefulness in using PAN beads in removing EE2 from synthetic aqueous solutions, also at concentrations higher than those measured in the environment.

\section{Abbreviations}

$\mathrm{C}_{0}$ : Initial pollutant concentration $\left(\mathrm{mg} \mathrm{L}^{-1}\right), \mathrm{C}_{\mathrm{e}}$ : Equilibrium liquid-phase concentration $\left(\mathrm{mg} \mathrm{L}^{-1}\right), \mathrm{q}_{\mathrm{e}}$ : Equilibrium solidphase concentration ( $\left.\mathrm{mg} \mathrm{g}^{-1}\right), \mathrm{q}_{\mathrm{t}}$ Amount of pollutant adsorbed at time $t$ for $\mathrm{mg}$ of adsorbent $\left(\mathrm{mg} \mathrm{g}^{-1}\right), \mathrm{q}_{\max }$ : Maximum adsorption capacity $\left(\mathrm{mg} \mathrm{g}^{-1}\right) \mathrm{t}$ : Time $(\mathrm{min}), K_{\mathrm{F}}$ Constant of Freundlich isotherm $\left(\mathrm{mg} \mathrm{g}^{-1}\right)\left(\mathrm{L} \mathrm{mg}^{-1}\right)^{1 / \mathrm{n}}, K_{\mathrm{L}}$ : Constant of Langmuir isotherm $\left(\mathrm{L} \mathrm{mg}^{-1}\right), \mathrm{K}_{\mathrm{D}-\mathrm{R}}$ : Dumwald-Wagner constant $\left(\mathrm{min}^{-1}\right), \mathrm{K}_{\mathrm{T}}$ andB: Constants of Tempkin isotherm: $\left(\mathrm{L} \mathrm{g}^{-1}\right)$ and $\left(\mathrm{J} \mathrm{mol}^{-1}\right)$, respectively, $\mathrm{K}_{\mathrm{ad}}$ Dubinin- Radushkhevich constants $\left(\mathrm{mol}^{2} \mathrm{~J}^{-2}\right), \mathrm{K}_{1}$ : Rate constant of pseudo-first-order kinetic model $\left(\mathrm{min}^{-1}\right), \mathrm{K}_{2:}$ Rate constant of pseudo-first, order kinetic model $\left(\mathrm{g} \mathrm{mg}^{-1} \mathrm{~min}^{-1}\right), \alpha$ and $\beta$ :Constant in Elovich's equation: $\left(\mathrm{mg} \mathrm{g}^{-1} \mathrm{~min}^{-1}\right)$ and $\left(\mathrm{g} \mathrm{mg}^{-1}\right)$, respectively, $K_{\text {id: }}$ Rate, constant of intraparticle diffusion model ( $\left.\mathrm{mg} \mathrm{g}^{-1} \mathrm{~min}^{-0.5}\right)$, C: Constant that gives idea about the thickness of the boundary layer (mg $\left.\mathrm{g}^{-1}\right), \mathrm{R}$ : Universal gas constant $\left(8.314 \mathrm{~J} \mathrm{~mol}^{-1} \mathrm{~K}^{-1}\right), \mathrm{T}$ : Absolute
Temperrature (K), $R_{\mathrm{L}}$ Dimensionless constant separation factor $R^{2}$ : Regression correlation coefficient.

\section{Introduction}

Endocrine disrupting chemicals (EDCs) constitute a group of organic pollutants with increasing negative impact on the environment as well as on human and animal health. EDCs interfere with the function of the endocrine system by blocking or mimicking the normal activity of hormones, affecting their synthesis or metabolism, and altering hormone receptor levels [1]. Compounds exhibiting endocrine disrupting activities include a broad range of chemicals, among which steroid estrogens, both natural and synthetic. The synthetic estrogen 17- $\alpha$-ethinylestradiol, EE2, is recognized as one of the EDCs with higher disrupting potency $[2,3]$. EE2, derived from the natural hormone estradiol E2, known also as $17-\beta$-estradiol, is mainly used in the formulation of oral contraceptives. Thus EE2 and E2 are widely excreted by humans and animals in urine and feces as active free forms or inactive glucuronide and sulfate conjugates. EE2 ends up in the environment through discharge of wastewater treatment plant (WWTP) effluents. Many studies 
have reported the presence of E2 and EE2 in waste and surface waters, in concentrations ranging from $\mathrm{ng} \mathrm{L^{-1 }}$ and $\mu \mathrm{g} \mathrm{L}^{-1}$ levels [4-10]. The presence of estrogens in the environment is an emerging problem due to the harmful effects on wildlife and humans, even at ng $\mathrm{L}^{-1}$ levels. Concerning the wildlife, EE2 has been shown to cause adverse reproductive effects, such as increased synthesis and secretion of vitellogenin in male subjects or changes in gonad somatic index in female Pimephalespromelas [11,12]. More interesting are also the recent papers concerning the reproductive systems in zebra fish [13,14] and in Pimephalespromelas [15]. However the effects of synthetic steroids on fish reproduction are not limited to laboratory exposures. Some researchers [16] conducted a seven-year experimentation on a whole lake in Ontario investigating the effects of EE2 on a population of fathead minnows. The first two years were employed for pre-exposure studies constituting the control, the subsequent three years for exposure studies, and the remaining two years for studying the post-exposure effects. Low levels of exposure $(5-6 \mathrm{ng} / \mathrm{L})$ for the three-year period resulted in the feminization of male fish and reduced gonad development. Females also produced vitellogenin beyond their normal breeding season, suggesting an altered reproductive season. The chronic exposure of fathead minnows to EE2 ultimately resulted in almost extinction of the fish population in the lake used for experimentation.

Concerning the human beings, besides the therapeutic use, EE2 reaches the humans through the food chain, water included, owing its potential to bioaccumulate.

Having in mind these risks it becomes imperative to remove from the environment EDCs, and in particular estrogenic steroid hormones. For all these reasons, the European Union has recently added E2 and EE2 to a new "watch list" of emerging aquatic pollutants included in the Water Framework Directive [17].

Since the existing sewage treatment plants have not been designed for the removal of endocrine disruptors, they are not effective barriers to the retention of these emerging pollutants. EE2, therefore, is continuously discharged into the environment. Subsidiary processes, therefore, are used before the release of water effluents into the environment to avoid the risks caused by EDCs in aquatic environments.Three main classes of processes have been utilized: physical, physicochemical and biological. Many times some of these processes have been simultaneously applied [18].

Physical processes are membrane filtration and adsorption. Membrane filtration is a process in which a membrane operates as a separation barrier, and certain substances can pass through it while others are retained. Adsorption is based on the uptake of the pollutant (adsorbate) from the aqueous phase onto a solid phase (adsorbent) and occurs or onto activated sludge or on adsorbent materials.

The physico-chemical processes are the advanced oxidation processes (AOPs) which refer to cases in which the oxidation of organic contaminants occurs primarily through reactions with hydroxyl radicals $* \mathrm{OH}$. AOPs typically involve two stages: The formation of $* \mathrm{OH}$, and the reaction of these oxidants with the organic contaminants in water. Advanced oxidation processes include photolysis, photocatalysis, sonolysis.

Biological processes, classified as bioremediation processes, occur using bacteria from activated and anaerobic sludge, enzymes or plants. In the last years our research has been focused on bioremediation of EDCs by means of immobilized enzymes working in bioreactors operating under isothermal or non-isothermal conditions [19-22].

In this paper we have focused our attention on the adsorption process considering the low cost of the adsorbent materials usually employed and the large employment of this process in the removal of dyes, ions and endocrine disruptors [23-32]. We have pursued the removal of EE2 by absorption on Polyacrylonitrile (PAN) beads. PAN beads have been chosen as adsorbent material owing to our previous experience in their use as enzyme carriers in bioremediation of aqueous solutions polluted by EDCs $[21,33,34]$ and since they have been already usefully used by other authors in adsorption process [26]. Kinetic studies and adsorption equilibrium data have been obtained. Experimental data have been treated using adsorption isotherm models and adsorption kinetic models. In addition, adsorption mechanisms have been discussed and postulated.

\section{Experimental}

\section{Materials}

Acrylonitrile, Sodium Nitrate, Glycerin, 17- $\alpha$-ethinylestradiol, Dimethylformamide, and Acetonitrile were purchased from Sigma-Aldrich (Milan, Italy) and used without further purification.

\section{Methods}

\section{Preparation of PAN Beads}

Acrylonitrile powder (54 g), $\mathrm{LiNO}_{3}(3 \mathrm{~g})$ and Glycerin (9 g) were dissolved in $234 \mathrm{~mL}$ of Dimethylformamide. The homogenized mixture was gently pipetted and precipitated in distilled water. The obtained beads were water-washed and immersed for $24 \mathrm{~h}$ in a glycerin aqueous solution $30 \%(\mathrm{v} / \mathrm{v})$. After this step, the beads were dried in an oven at $70{ }^{\circ} \mathrm{C}$ for a time sufficient to reach a constant weight. The average diameter of beads was $3.5 \mathrm{~mm} \pm 0.5 \mathrm{~mm}$, as measured with a caliper. This measure was confirmed by SEM observations.

\section{Characterization of PAN beads}

Scanning Electronic Microscopy observations: SEM analysis were performed on a FEI Quanta 200 FEG SEM in high vacuum using a secondary electron detector and an acceleration voltage of $20 \mathrm{kV}$. Before analysis, samples were coated with a 15 $\mathrm{nm}$ thick $\mathrm{Au} / \mathrm{Pd}$ layer with a sputter coating system.

FT-IR spectroscopy: A Perkin Elmer Spectrum One FT-IR spectrometer, equipped with a MIR TGS detector, has been used to record FT-IR spectra. Spectral acquisitions were performed with $\mathrm{KBr}$ pellets. All spectra have been collected using 4 scans in the range from 2400 to $900 \mathrm{~cm}^{-1}$ with a $4 \mathrm{~cm}^{-1}$ spectral resolution. Measure- 
ments were analyzed in triplicate. The spectra have been analyzed using the application routines provided by the software package ("Spectrum" User Guide, Perkin Elmer Inc.USA)

\section{7-a-ethinylestradiol determination}

EE2 concentration in aqueous solution was measured by high-performance liquid chromatography, HPLC, using an LC20AT apparatus (Shimadzu, Kyoto) equipped with a UV/Visible Diode Array detector (SPDM20A, Germany) at a flow-rate of $1.3 \mathrm{~mL} / \mathrm{min}$. All analyzed samples were pre-filtered through a $0.2 \mu \mathrm{m}$ Cellulose Mixed Esters syringe filter (Macherey-Nagel GmbH \& Co. KG, Germany). The mobile phase consisted of acetonitrile/water. The chromatographic determination was performed by using a gradient: in 3 min acetonitrile from 50 to $90 \%$; for $4 \mathrm{~min}$ acetonitrile/water $90 \% \mathrm{v} / \mathrm{v}$; in $1 \mathrm{~min}$ acetonitrile from 90 to $50 \%$. The retention time was found to be $4 \mathrm{~min}$. By plotting as a function of concentration the peak area at known concentrations, it is possible to obtain a calibration curve from which unknown EE2 concentrations can be determined. The low detection limit was $1 \mu \mathrm{M}$, the extension of the linear range was up to $100 \mu \mathrm{M}$, the measure repeatability in the same experiment was less than $1 \%$, while the repeatability between different experiments at the same concentration was no more than $3.5 \%$

\section{Classical adsorption measurements}

In batch experiments, $26 \mathrm{~g}$ of PAN beads were added into a $250 \mathrm{~mL}$ Erlenmeyer flask with plastic stopper, containing 60 $\mathrm{mL}$ of EE2 solution. The flasks were shaken at $300 \mathrm{rpm}$ at room temperature $\left(25 \pm 1^{\circ} \mathrm{C}\right)$. During the time, $200 \mu \mathrm{L}$ of the solution were extracted and their 17- $\alpha$-ethinylestradiol concentration determined by using HPLC.

To investigate the kinetics of adsorption, the effect of contact time on the adsorption capacity of PAN beads was studied. Isotherm studies were performed using different initial EE2 concentration, ranging from 3.2 to $332 \mu \mathrm{M}$. Two direct parameters are obtained from these studies: the Percentage Removal at $\mathrm{t}$ time, $\mathrm{PR}_{\mathrm{t}}$, and the Absorption Capacity (AC). The $\mathrm{PR}_{\mathrm{t}}$ is calculated using the expression

$$
P R_{e}(\%)=\frac{C_{o}-C_{e}}{C_{o}} \times 100
$$

where $\mathrm{C}_{0}$ is the initial EE2 concentration expressed in the proper units $(\mathrm{mg} / \mathrm{L})$ and $\mathrm{C}_{\mathrm{t}}$ is the residual concentration in the solution at time $t$, expressed in the same units. When $C_{t}$ becomes $\mathrm{C}_{e}$,i. e. the EE2 concentration at equilibrium, equation 1 becomes

$$
P R_{e}(\%)=\frac{C_{0}-C_{e}}{C_{o}} \times 100
$$

The Equilibrium Adsorption Capacity $(\mathrm{AC})_{\mathrm{e}}$ is calculated according to equation

$$
(\llbracket A C) \rrbracket_{\mathrm{e}}(\mathrm{mg} / \mathrm{g})=\frac{\left(C_{o}-C_{e} V\right.}{W}
$$

Where $\mathrm{C}_{0}$ and $\mathrm{C}_{\mathrm{e}}$ are the initial and equilibrium concentration of EE2 (mg/L), respectively, $\mathrm{V}$ is the volume of solution (L), and $\mathrm{W}$ is the mass $(\mathrm{g})$ of PAN beads. Preliminarily to every experimental approach, the adsorption capacity of PAN beads as function of $\mathrm{pH}$ of the solution must be assessed in order to find the best $\mathrm{pH}$ condition for adsorption.

\section{Adsorption isotherm models}

Four adsorption isothermal models are used to draw insights on the adsorption mechanism and on the surface properties of the adsorbent: the Langmuir model, the Freundlich model, the Dubinin-Radushkevich isotherm and the Tempkin isotherm. The first two models, in particular, are utilized for distinguishing between homogeneous monolayer (Langmuir) or heterogeneous (Freundlich) adsorbent surface.

Each model is represented by a linearized equation:

$$
\text { Langmuir isotherm: } \frac{C_{e}}{q_{e}}=\frac{1}{q_{\max } K_{L}}+\frac{C_{e}}{q_{\max }}
$$

Freundlich isotherm: In $\mathrm{q}_{\mathrm{e}}=\operatorname{In} \mathrm{K}_{\mathrm{F}}+\frac{1}{n} \operatorname{In} \mathrm{C}_{\mathrm{e}}$

Dubinin - Radushkevich isotherm: In $\mathrm{q}_{\mathrm{e}}=$ In $\mathrm{q}_{\mathrm{D}-\mathrm{R}}-\mathrm{K}_{\mathrm{ad}^{\varepsilon}}{ }^{2}$

$$
\text { Tempkin isotherm: } \mathrm{q}_{\mathrm{e}}=\frac{R T}{b_{T}} \operatorname{In} K_{T} C_{e}=B \operatorname{In} K_{T}+B \text { In } C_{e}
$$

To choice the right model among the four, the $\mathrm{R}^{2}$ value of each linearized equation will be relevant.

Concerning equation 4 , when $C_{e} / q_{e}$ is plotted versus $C_{e}$ a straight line is obtained, from which the values of $\mathrm{q}_{\max }$ and $\mathrm{K}_{\mathrm{L}}$ are calculated. An interesting parameter correlated to the $\mathrm{K}_{\mathrm{L}}$ constant is the dimensionless $\mathrm{R}_{\mathrm{L}}$ parameter defined by the formula:

$$
R_{L}=\frac{1}{1+C_{0} K_{L}} \times 100
$$

where $\mathrm{C}_{0}(\mathrm{mg} / \mathrm{L})$ is the initial pollutant concentration and $\mathrm{K}_{\mathrm{L}}$ the Langmuir isotherm constant. When $\mathrm{R}<1$ the absorption is favorable, for $\mathrm{R}=0$ the absorption is irreversible, while for $\mathrm{R}=1$ the absorption is linear, and for $\mathrm{R}>1$ the absorption is unfavorable.

Similarly, with reference to equation 5 , where $q_{e}$ is the amount of pollutant adsorbed at equilibrium $(\mathrm{mg} / \mathrm{g})$ and $\mathrm{C}_{e}$ is the equilibrium concentration of the adsorbate $(\mathrm{mg} / \mathrm{L})$, when $\ln \mathrm{q}_{\mathrm{e}}$ is plotted against $\ln \mathrm{C}_{\mathrm{e}}$, a straight line with slope $1 / \mathrm{n}$ and intercept $\ln \mathrm{K}_{\mathrm{F}}$ is obtained. $\mathrm{K}_{\mathrm{F}}$ and $\mathrm{n}_{f}$ are Freundlich constants related to the adsorption capacity and adsorption intensity, respectively. $\mathrm{K}_{\mathrm{F}}$ is roughly an indicator of the adsorption capacity, and $\mathrm{n}$ gives an indication of adsorption effectiveness.

Considering equation 6 , where $\mathrm{q}_{\mathrm{e}}$ is the amount of removed pollutant per unit of adsorbent mass $\left(\mathrm{mg} / \mathrm{g}\right.$ ) and $\mathrm{q}_{\mathrm{D}-\mathrm{R}}$ is the adsorption capacity $(\mathrm{mg} / \mathrm{g})$, the plot of $\ln \mathrm{q}_{\mathrm{e}}$ as a function of $\varepsilon^{2}$ allows calculating the values of $\mathrm{K}_{\mathrm{ad}}$ and $\mathrm{q}_{\mathrm{D}-\mathrm{R}}$ ? ? is calculated by using the equation: 


$$
\varepsilon=R T \operatorname{In}\left(1+\frac{1}{C_{e}}\right)
$$

Where $\mathrm{R}$ is the gas constant $\left(8.314^{*} 10^{-3} \mathrm{~kJ} \mathrm{~mol}^{-1} \mathrm{~K}^{-1}\right)$, and $\mathrm{T}$ is the absolute temperature $(K)$. The constant $K_{\mathrm{ad}}$ gives the mean free energy of sorption per molecule of the sorbate and it is linked to $E$, which gives the energy when a mole of pollutant transferred from infinity to the surface of the solid in the solution though the equation

$$
E=\frac{1}{\sqrt{2 K_{\mathrm{ad}}}}
$$

This energy $\mathrm{E}$ gives information about the physical and chemical features of the sorption process.

Similarly, considering equation 7 , the linear plot of $\mathrm{q}_{e}$ versus $\ln \mathrm{C}_{e}$ enables the determination of the isotherm constants $\mathrm{B}$ and $K_{T}$ from its slope and intercept, respectively. $K_{T}$ and $\mathrm{B}$ are respectively the Tempkin equilibrium binding constant, corresponding to the maximum binding energy, and the Tempkin constant related to the heat of adsorption.

\section{Adsorption kinetic models}

Kinetic studies describe the rate of adsorption and how this parameter controls the equilibrium time. To examine the controlling rates of the adsorption processes and to test the goodness of the experimental data the "Pseudo-first-order kinetic model", "Pseudo-second-order kinetic model" and "Elovich model" are used.

Also in this approach to choice among the different models, the $\mathrm{R}^{2}$ value of each of the linearized equations describing each model will be the principal criterion.

The pseudo-first-order Langergren's model [35], once integrated the differential equation representing the model, i.e. the equation

$$
\frac{d q}{d t}=K_{1}\left(q_{e}-q_{t}\right)
$$

Becomes

$$
\text { In }\left(q_{e}-q_{t}\right)=\text { In } q_{e}-k_{1} t
$$

The adsorption rate constant $\mathrm{k}_{1}$ can be experimentally determined by the slope of the linear plot of $\ln \left(q_{e}-q_{t}\right)$ vs. $t$.

The rate of adsorption for the modified pseudo-secondorder model [36] is expressed as:

$$
\frac{d q}{d t}=k_{2}\left(q_{e}-q_{t}\right)^{2}
$$

Which is linearized in the form

$$
\frac{t}{q_{t}}=\frac{1}{k_{2} q_{e}^{2}}+\frac{1}{q_{e}} t
$$

The intercept and the slope of the plot of $t / q_{t} v s$. $t$ give the $\mathrm{k}_{2}$ and $\mathrm{q}_{\mathrm{e}}$ values.

The Elovich model has recently applied to the adsorption process of pollutants from aqueous solutions [37,38].
The Elovich equation is:

$$
q_{t}=\alpha+\beta \text { Int }
$$

Where $\alpha$ is the initial adsorption rate $\left(\mathrm{mg} \mathrm{g}^{-1} \mathrm{~min}^{-1}\right)$, and $\beta$ is related to the extent of surface coverage and activation energy for chemisorptions $(\mathrm{g} / \mathrm{mg})$.

When the Elovich kinetic is applicable, the plot of $q_{t}$ versus $\ln t$ gives a linear relationship. From the slope and intercept of the equation, the Elovich parameters $\alpha$ and $\beta$ are calculated.

\section{Adsorption mechanisms}

The adsorption process can be considered as a series of three sequential steps:

1) Film diffusion, during which the adsorbate goes towards the external surface of the adsorbent;

2) Particle diffusion, during which the adsorbate molecules travel within the pores of the adsorbent;

3) Adsorption of the adsorbate molecules on the internal surface of the adsorbent.

The third step is so very fast that cannot be considered as a rate limiting step and therefore can be disregarded. When the first step is greater than the second, the process rate is governed by particle diffusion, when the contrary occurs the film diffusion governs the process. When the external transport is equivalent to the internal transport, the formation of a liquid film around the adsorbent particles occurs, and the adsorbate diffusion follows its concentration gradient.

To solve this problem, we examined our results by means of three consolidated models: the Dumwald-Wagner model, the Intraparticle Diffusion model, and the Boyd model. Also in this approach to choice among the different models, the $\mathrm{R}^{2}$ value of each of the linearized form describing the models will be the significant criterion.

The diffusion rate equation of Dumwald-Wagner [39] inside a particulate is express by:

$$
\log \left(1-F^{2}\right)-\frac{K_{D}-W}{2} .303 t
$$

Where $\mathrm{K}_{\mathrm{D}-\mathrm{W}}\left(\mathrm{min}^{-1}\right)$ is the diffusion rate constant, and $\mathrm{F}$ is the adsorption percent calculated by $\mathrm{q}_{\mathrm{t}} / \mathrm{q}_{\mathrm{e}}$.

The linear plot of $\log \left(1-\mathrm{F}^{2}\right)$ versus $t$ indicates the applicability of this model considering the correlation coefficient $\mathrm{R}^{2}$.

The equation representing the intraparticle diffusion model based on the Weber and Morris theory, who found an empirical relationship according to which adsorption occurs proportionally to $t^{1 / 2}$ rather than with $t[39,40]$. According to this theory the following equation is obtained:

$$
q_{e}=B \operatorname{In~} \mathrm{K}_{\mathrm{T}}+B \text { In } \mathrm{C}_{\mathrm{e}}
$$

The plot of $\mathrm{q}_{\mathrm{t}}$ versus $\mathrm{t}^{1 / 2}$ is a straight line whose slope is the 
intraparticle diffusion rate $\mathrm{k}_{\mathrm{id}}$. The value of $\mathrm{C}$ gives an idea about the thickness of the boundary layer: the larger the intercept, the greater the boundary layer effect. When $\mathrm{C}$ is equal to zero, the intraparticle diffusion process is involved and represents the step rate limiting.

The Boyd model [41] is used to predict the rate limiting step involved in the absorption process. Kinetic data are expressed according to the Boyd equation:

$$
B_{t}=-0.4978-\operatorname{In}(1-F)
$$

Where $\mathrm{F}$ represents the adsorbent fraction adsorbed at $\mathrm{t}$ time, calculated as $\mathrm{F}=\mathrm{q}_{\mathrm{t}} / \mathrm{q}_{\mathrm{e}}$ in which $\mathrm{q}_{\mathrm{t}}$ and $\mathrm{q}_{\mathrm{o}}$ are the adsorbate amounts at $\mathrm{t}$ time and at equilibrium, respectively.

Once calculated $B_{t}$ at each value of $F$, and hence of $t$, the plot of $B_{t}$ versus $t$ allows to establish the rate limiting diffusion step. Indeed, film diffusion governs the rate limiting of the adsorption process if the straight lines no pass through the axis origin

\section{Results and Discussion}

\section{Preliminary results}

In figure 1 a simple characterization of PAN beads is shown by using scansion electronic microscopy figure $1 \mathrm{a}$ and FT-IR spectrum (Figure 1b). Figure 1a confirms the spherical shape and the dimensions of the beads. In figure $1 \mathrm{~b}$ the FT-IR spectrum of PAN-beads in the region $2400-900 \mathrm{~cm}^{-1}$ is reported. The most important structures are: the band at $2245 \mathrm{~cm}^{-1}$ related to the stretching of the triple bond $\mathrm{C} \mathrm{N}$; the large structure with the maximum located at 1735 and at $1634 \mathrm{~cm}^{-1}$ assigned to $\mathrm{C}=0$ stretching and to $\mathrm{C}=\mathrm{C}$ stretching of vinyl group, respectively; the band at 1447 attributed to $\mathrm{CH}_{2}$ bending; the peaks at 1380 $\mathrm{cm}^{-1}$ and at $1040 \mathrm{~cm}^{-1}$ assigned to $\mathrm{NO}_{3}$ stretching of nitrate group [42, 43].

As reported in methods, to know the best yield in EE2 removal by PAN beads, their adsorption capacity has been assessed as a function of $\mathrm{pH}$ of the synthetic solutions. Results are reported in figure 2 as relative adsorption capacity (\%) as a function of $\mathrm{pH}$. The experimental data refer to the adsorption capacity after a contact time of $80 \mathrm{~min}$, initial EE2 concentration and temperature being respectively equal to 5 $\mathrm{uM}$ and to $25 \pm 0.5^{\circ} \mathrm{C}$.

Figure 2: Relative Adsorption Capacity of PAN Beads towards EE2 as a function of $\mathrm{pH}$ of the solution.

From the figure clearly it emerges that the optimum $\mathrm{pH}$ for EE2 adsorption on PAN beads occurs at $\mathrm{pH}$ 5.0. This result can be indicative of the presence of a net negative charge on the PAN surface. This charge alters the microenvironment around the bead and hence the $\mathrm{pH}$ conditions there existing. Taking into account this result henceforward all experiments have been performed at $\mathrm{pH}$ 5.0.

An example of a crude result of our experimentation is illustrated in figure $3 a$ showing the decrease of the EE2 concentration as a function of the contact time of the solution with the PAN beads. The experimental conditions were: $\mathrm{C}_{0}=3.2$ $\mu \mathrm{M}$, temperature $=298 \mathrm{~K}$, and $\mathrm{pH}=5.0$. In figure $3 \mathrm{~b}$ the results of figure 3 a have been elaborated as percentage of EE2 removal during the time, according to equation 1 . Figure $3 \mathrm{c}$ shows the time dependence of $\mathrm{q}_{\mathrm{t}}$ for the experimental case of figure 1a. Since we used different EE2 concentrations in contact with the same amount of PAN beads, in figure $3 d$ the $q_{t}$ value for each solution has been reported as a function of contact time. Results in figure $3 \mathrm{~d}$ clearly evidence how at the same time the $q_{t}$ values, as expected, increase with the increase of the initial EE2 concentration used. Each experimental point in the figures is the average of three independent experiments. The standard error never exceeded $4.5 \%$.

Figure 3: a) Absolute removal as a function of time; b) Percentage removal as a function of time; c) $\mathrm{q}_{\mathrm{t}}$ as a function of time. Experimental conditions $\mathrm{C}_{0}=3.2 \mu \mathrm{M}$ and $\mathrm{T}_{\mathrm{av}}=25^{\circ} \mathrm{C}$.

d) $q_{t}$ as a function of time for each of used EE2 concentrations.

In figure 4 the adsorption capacity of the PAN beads is reported as a function of the initial EE2 concentration after a contact time of $100 \mathrm{~min}$. The figure shows that the adsorption capacity linearly increases $\left(\mathrm{R}^{2}=0.999\right)$ with the increase of the initial EE2 concentration, so indicating the excess of the number of adsorption sites on the adsorbate molecules.
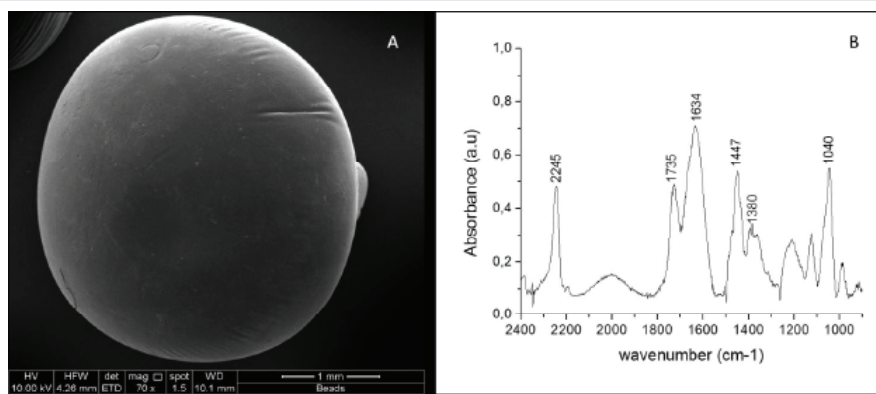

Figure 1: a) SEM of the shape and dimension of a PAN bead; b) FT-IT spectrum of the composition of a PAN bead.

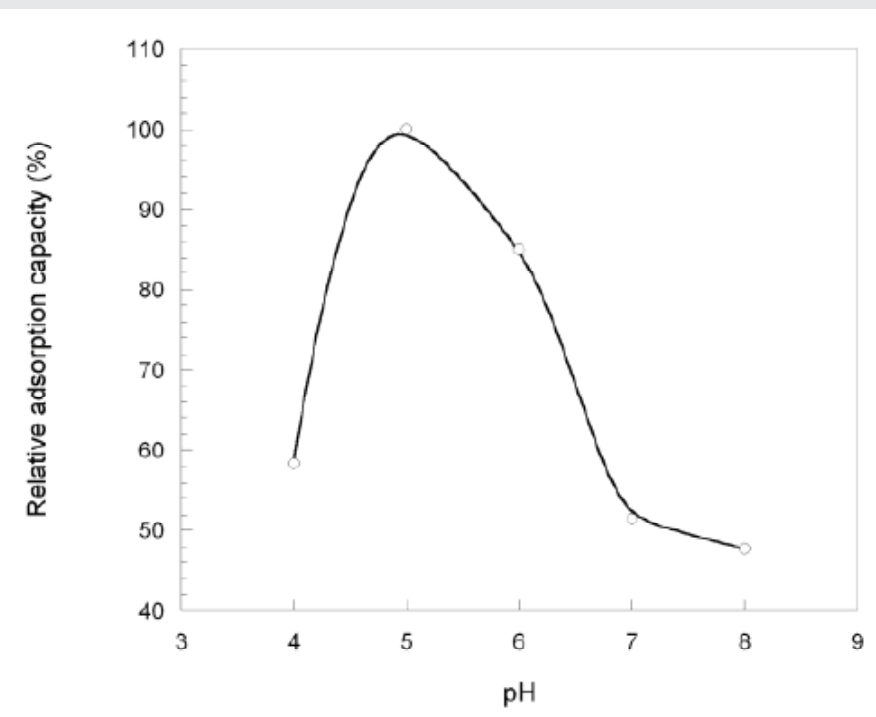

Figure 2: Relative Adsorption Capacity of PAN Beads towards EE2 as a function of $\mathrm{pH}$ of the solution. 
a

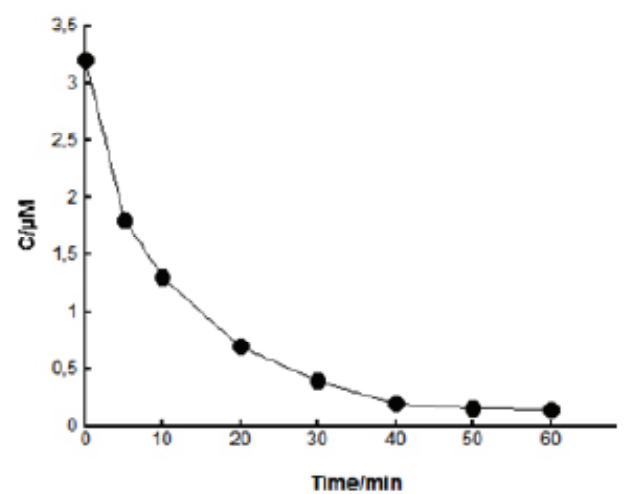

c

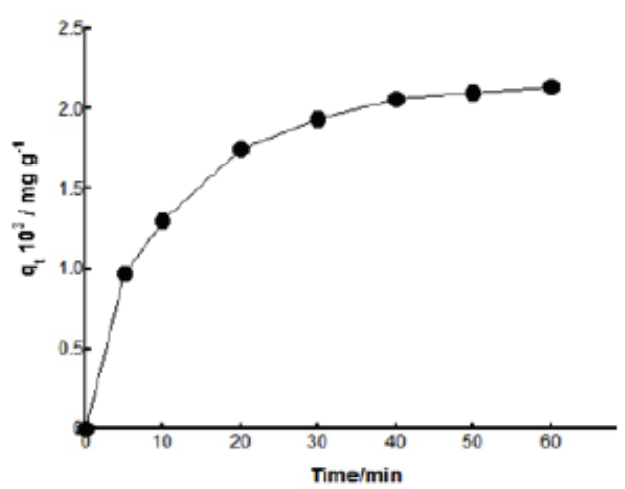

b

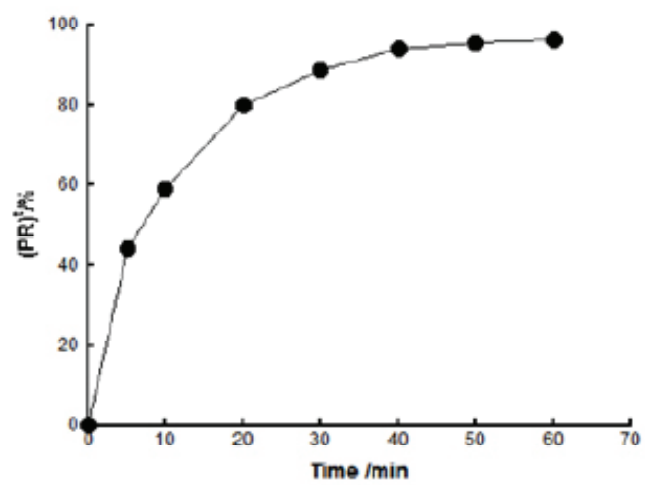

d

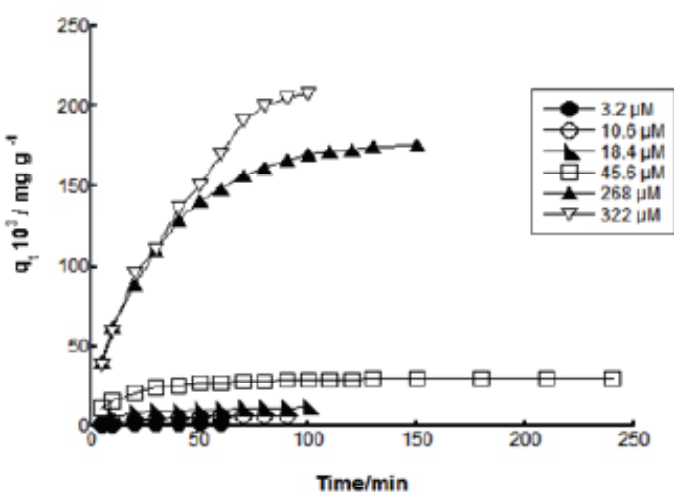

Figure 3: a) Absolute removal as a function of time; b) Percentage removal as a function of time; c) qt as a function of time. Experimental conditions $\mathrm{CO}=3.2 \mu \mathrm{M}$ and Tav $=25^{\circ} \mathrm{C}$.

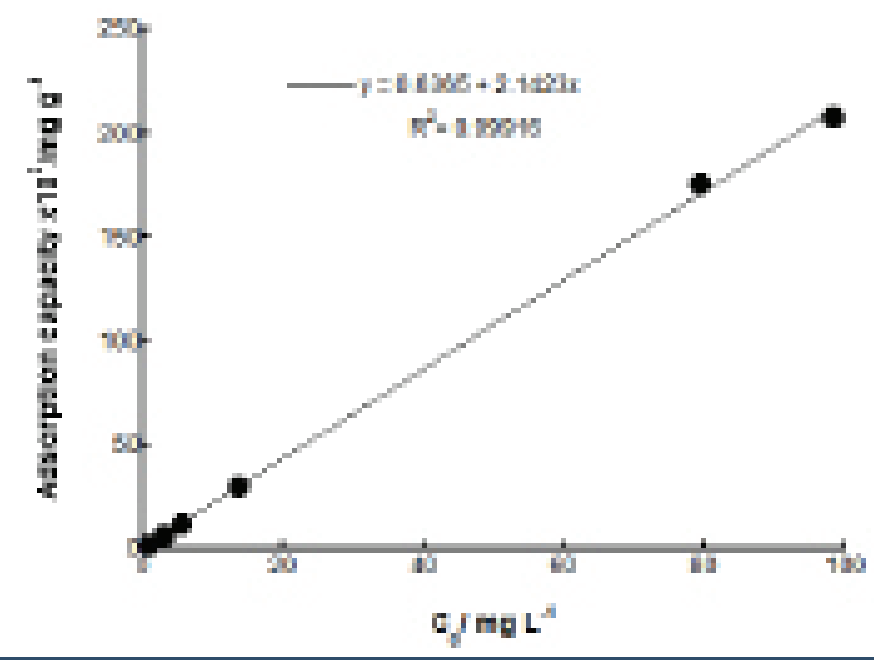

Figure 4: PAN adsorption capacity as a function of initial EE2 concentration.

Figure 4: PAN adsorption capacity as a function of initial EE2 concentration.

Results in figures 3, 4 show the usefulness of PAN beads in removing EE2 by adsorption, but not give any information on the adsorption mechanism. This information is provided in the following sections.

\section{Adsorption isotherm models}

In figure $\mathbf{5}$ the experimental data obtained in this research are analyzed according to the four isotherm models reported in the Methods to establish the best model for accounting the isothermal adsorption of EE2. The choice will be made according to the $\mathrm{R}^{2}$ value of the linearized equation characteristic of each model. Adsorption isotherms are mathematical models describing the distribution of the adsorbate among solid and liquid phases. For the adsorption isotherms, the initial EE2 concentration was varied, whereas the $\mathrm{pH}(\mathrm{pH}=5)$ and temperature of the solution $\left(\mathrm{T}=25^{\circ} \mathrm{C}\right)$, the agitation speed, and the sorbents weight in each sample were held constant. Data about the four isothermal models are compiled in figure $\mathbf{5}$. Figure 5a reports the elaboration of experimental data plotted according to equation 4 representing the Langmuir isotherm model. In figure $\mathbf{5 b}$ the plot of equation 5 is done according to the Freundlich model. Figures $\mathbf{5 c}, \mathbf{d}$, in turn, represent the Dubinin-Radushkevich and Tempkin models, plotted according to equation 6 and 7, respectively.

Figure 5: Adsorption isotherm models: a) Langmiur; b) Freundlich; c) Dubin-Radushkevich; d) Tempkin. In each panel the analytical equations best fitting the values of the experimental points are reported together with the $\mathrm{R}^{2}$ value of the correlation coefficient of the respective straight lines. 
a

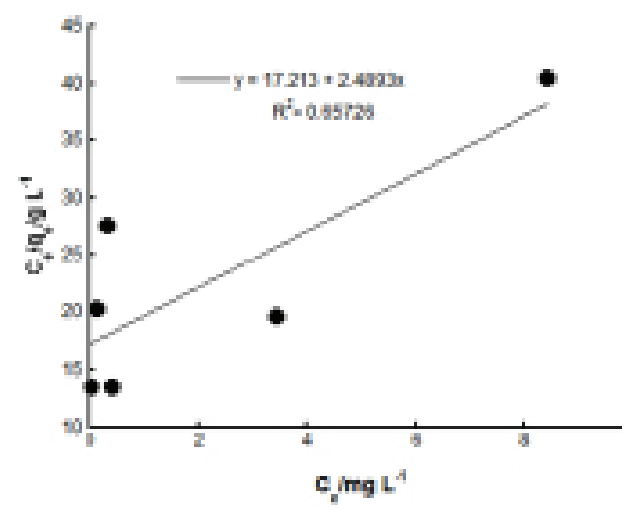

c

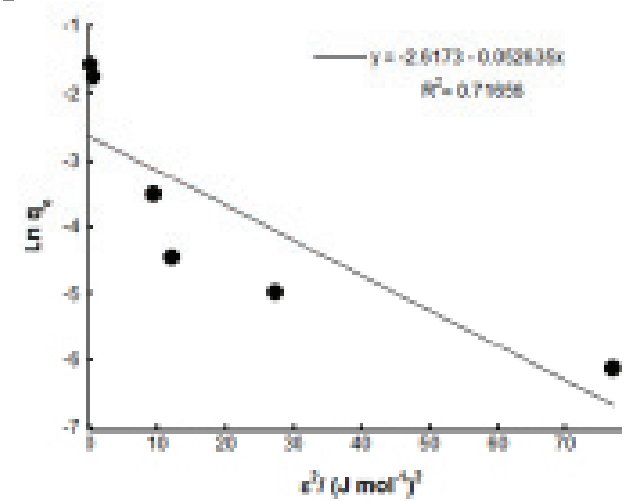

b

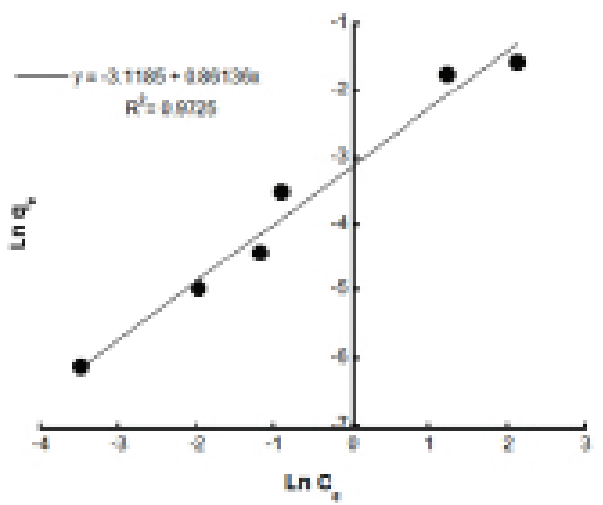

d

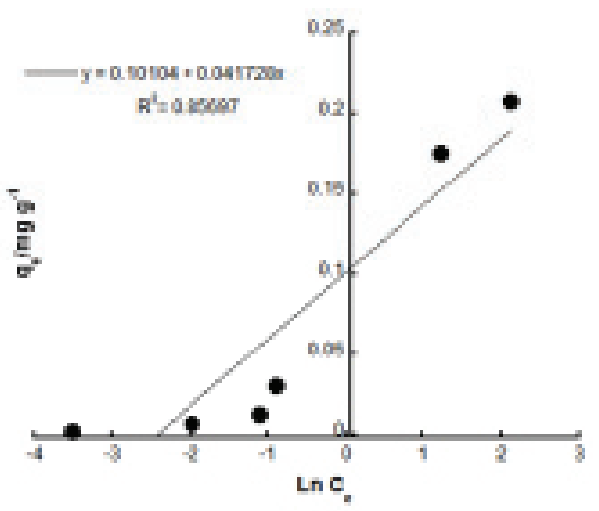

Figure 5: Adsorption isotherm models: a) Langmiur; b) Freundlich; c) Dubin-Radushkevich; d) Tempkin. In each panel the analytical equations best fitting the values of the experimental points are reported together with the R2 value of the correlation coefficient of the respective straight lines.

As reported in Methods, from the values of the slope and intercept of each equation it is possible to calculate the parameters characterizing each isothermal model. These parameters are listed in table $\mathbf{1}$. Looking at the $\mathrm{R}^{2}$ values (Table 1) it is possible to deduce that the isotherm Freundlich model better accommodates to our adsorption experiments. This conclusion suggests: i) the absence of an homogeneous adsorbent surface, ii) the absence of homogeneous energy site or limited levels of adsorption, and iii) that electrostatic forces play a significant role in the adsorption mechanism of EE2 by PAN beads.

$\mathrm{R}^{2}$ values in table 1 are compiled with the standard deviations (S.D.) calculated by means of the equation :

S.D. $(\%)=100 \times\left\{\frac{\Sigma_{N}\left(1-\left(q_{t, c a l} / q_{t, \mathrm{exp}}\right)\right)^{2}}{N}\right\}^{1 / 2}$

$\mathrm{R}^{2}$ values are congruous with S.D. values: greater is $\mathrm{R}^{2}$, smaller is S.D.

Before concluding this section, it is interesting to consider Figure 6 where the $R_{L}$ values, calculated according to eq. (8), have been reported as a function of the initial EE2 concentration.

Remembering the meaning of $\mathrm{R}_{\mathrm{L}}$ and being this value at all concentration smaller than the unit it follows that the adsorption process is favorable.

\section{Adsorption kinetics models}

Kinetic studies are necessary in an adsorption process because they allow to calculate the uptake rate of the adsorbate and give information about the control of the residual time of the whole adsorption process. As reported in Methods, three different kinetic models, i.e. pseudo first-order, pseudo second-order and Elovich, were selected in this study for describing the EE2 adsorption process. The results relative at each model are shown in figure 7

Figure $7 \mathbf{a}$ illustrates the results regarding the pseudofirst-order kinetic model by plotting the experimental data according to equation 12. The value of the first-order rate constant $k_{1}$ and the value of the correlation coefficient $R^{2}$, obtained from the slope of the plot $\ln \left(\mathrm{q}_{\mathrm{e}}-\mathrm{q}_{\mathrm{t}}\right)$ versus time for each used concentration, are reported in table 2. From the table, it is possible to observe that the correlation coefficients, ranging from 0.93 to 0.99 , are high enough for the different EE concentrations. However, the calculated values of $\mathrm{q}_{\mathrm{e}, \text { calc }}$, are smaller than the experimental ones, $\mathrm{q}_{\mathrm{e}, \text { exp. }}$, and differ enough, so indicating that the model is not appropriate to describe the adsorption process. 
Figure $\mathbf{7 b}$ reports the experimental results regarding the pseudo-second-order kinetic model by plotting the data according to equation 14 . The plot of $t / q_{t}$ versus $t$ gives, at each concentration, a linear relationship. The values of the calculated $\mathrm{q}_{\mathrm{e}, \text { calc }}$ and of $\mathrm{k}_{2}$ can be determined respectively from the slope and intercept of the analytical equation representing the straight line of each model. These values have been tabulated in table 3 together with the values of the correlation coefficients $\mathrm{R}^{2}$ and the S.D.

Based on linear regression values, the kinetics of EE2 adsorption onto PAN appears well described by the secondorder model. Also, considering that the calculated values of $\mathrm{q}_{\mathrm{e}, \text { calc }}$ from equation 14 are higher than the experimental ones, $\mathrm{q}_{\text {exp. }}$, and differ few from the latter, it is possible to draw the conclusion that the model is appropriate enough to describe the adsorption process. This finding suggests that the ratelimiting step in the adsorption process may be chemisorptions involving valent forces through the sharing or exchanging of electrons between sorbent and sorbate [15].In conclusion, the second-order rate expression fits the data better than the firstorder-rate model.

Figure 7c shows, according to equation 15, the plot of $q_{t}$ against lnt for the adsorption of different initial concentrations of EE onto PAN beads. From the slope and intercept of the linearization of the simple Elovich equation, the estimated Elovich parameters have been obtained and tabulated in table 4. The value of $\beta$ is indicative of the number of sites available for adsorption, while $\alpha$ is the adsorption quantity when lnt is equal to zero, i.e. the adsorption quantity when $t$ is one hour. From this table, it is possible to conclude that the simple Elovich equation fit well with the experimental data but less than the second-order-rate model.

To better choose between the different models, considering the different value of $\mathrm{R}^{2}$ as a function of the concentration, we have reported in the last column of tables 2-4 the average value of $\mathrm{R}^{2}$, i.e. $\mathrm{R}^{2}$ average for each model. According to these values, there are no doubts that the second order model better fits the experimental data.

Table 1: Langmuir, Freundlich, Dubinin - Radushkevich and Temkin isotherm constants and correlation coefficients.

\begin{tabular}{|c|c|c|c|c|}
\hline Isotherm & \multicolumn{4}{|c|}{ Constants } \\
\hline Langmuir & $q_{\max }\left(\mathrm{mg} \mathrm{g}^{-1}\right)$ & $\mathrm{K}_{\mathrm{L}}\left(\mathrm{L} \mathrm{mg}^{-1}\right)$ & $\mathbf{R}^{2}$ & S.D. ( \%) \\
\hline$\frac{C_{e}}{q_{e}}=\frac{1}{q_{\max } K_{L}}+\frac{C_{e}}{q_{\max }}$ & \multicolumn{4}{|c|}{0.400 .1450 .6527} \\
\hline \multirow{2}{*}{$\begin{array}{c}\text { Freundlich } \\
\text { In } \mathrm{q}_{\mathrm{e}}=\operatorname{In} \mathrm{K}_{\mathrm{F}}+\frac{1}{n} \operatorname{In} \mathrm{C}_{\mathrm{e}}\end{array}$} & $\begin{array}{l}\mathrm{K}_{\mathrm{F}}\left(\mathrm{mg} \mathrm{g}^{-1}\right) \\
\left(\mathrm{L} \mathrm{mg}^{-1}\right)^{1 / n}\end{array}$ & $1 / n$ & $\mathbf{R}^{2}$ & S.D. (\%) \\
\hline & \multicolumn{4}{|c|}{0.0441 .160 .9711} \\
\hline Dubinin-Radushkevich & $q_{D-R}\left(\mathrm{mg} \mathrm{g}^{-1}\right)$ & $\mathrm{K}_{\mathrm{ad}}\left(\mathrm{mol}^{2} / \mathbf{k} \mathbf{J}^{2}\right)$ & $\mathbf{R}^{2}$ & S.D. (\%) \\
\hline In $\mathrm{q}_{\mathrm{e}}=\operatorname{In} \mathrm{q}_{\mathrm{D}-\mathrm{R}}-K_{\mathrm{ad}} \varepsilon^{2}$ & \multicolumn{4}{|c|}{0.0730 .05260 .7237} \\
\hline Temkin & $\mathrm{B}\left(\mathrm{J} \mathrm{mol}^{-1}\right)$ & $\mathrm{K}_{\mathrm{T}}\left(\mathrm{L} \mathrm{g} \mathrm{g}^{-1}\right)$ & $\mathbf{R}^{2}$ & S.D. (\%) \\
\hline$q_{e}=B \operatorname{In} \mathrm{K}_{\mathrm{T}}+B \operatorname{In} \mathrm{C}_{\mathrm{e}}$ & \multicolumn{4}{|c|}{$41.711 .270 .86187 \%$} \\
\hline
\end{tabular}

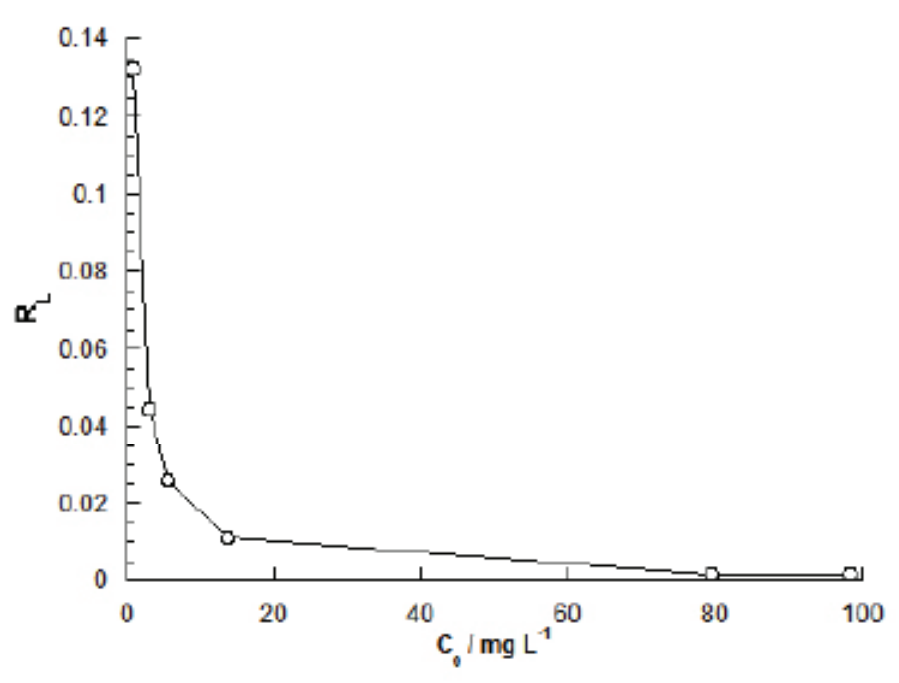

Figure 6: RL values as a function of the EE2 initial concentration.
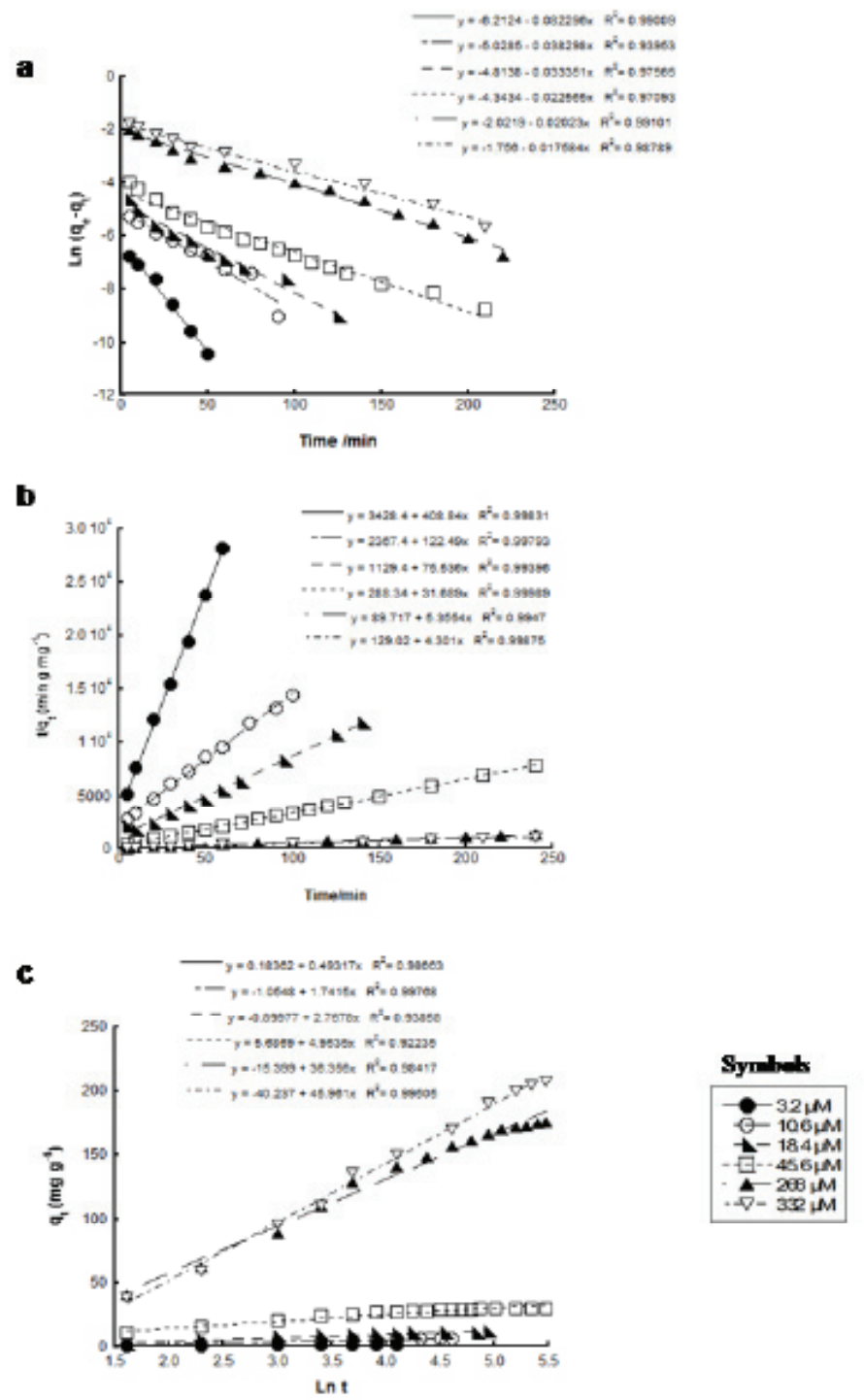

Figure 7: Isothermal adsorption kinetic models: a) Pseudo - first order; b) pseudo - second order c) Elovich model.

Citation: Mita L, Forte M, Rossi A, Adamo C, Rossi S, et al. (2017) Removal of 17-a Ethinylestradiol from Water Systems by Adsorption on Polyacrylonitrile Beads: Isotherm and Kinetics Studies. Ann Environ Sci Toxicol 2(1): 048-058. DOI: https://dx.doi.org/10.17352/aest.000012 


\section{Adsorption isotherm mechanisms}

As reported in Methods, a typical liquid/solid adsorption process involves three steps: film diffusion, intraparticle diffusion, and mass action. Mass action is a very rapid process and can be neglected in a kinetic study. Thus, the kinetic process of adsorption is always controlled by liquid film diffusion or by intraparticle diffusion. Therefore, adsorption diffusion models have been constructed Figure 8 to describe the process of film diffusion, also known as Dumwald-Wagner kinetic model, and/or intraparticle diffusion

In figure 8a our results have been elaborated as Log $\left(1-\mathrm{F}^{2}\right)$ versus the contact time for each of the initial EE2 concentrations, according to equation 16 . The resulting linear plots, together with the high values of the $\mathrm{R}^{2}$ coefficient, indicate the applicability of the Dumwald-Wagner kinetic model, characterized by equation 17 . The diffusion rate constants $\mathrm{K}_{\mathrm{D}-\mathrm{W}}$, along which the $\mathrm{R}^{2}$ values for each of initial concentration used, are reported in table 5 .

The intraparticle model is commonly used for identifying the adsorption mechanism. The intraparticle diffusion plot for EE2 adsorption onto PAN beads is given in figure $\mathbf{8 b}$, according to equation 17. Two separate linear portions are observedin

Table 2: Rate constants and correlation coefficient for the pseudo - first- order model at each initial EE2 concentration used.

\begin{tabular}{|c|c|c|c|c|c|c|}
\hline $\mathbf{C}_{\mathbf{o}}(\boldsymbol{\mu M})$ & $\mathbf{K}_{\mathbf{1}} / \mathbf{m i n}^{-1}$ & $\mathbf{q}_{\mathrm{e}, \text { alc }} / \mathbf{m g ~ g}^{-1}$ & $\mathbf{q}_{\mathrm{e}, \mathrm{exp}} / \mathbf{m g ~ g}^{-1}$ & $\mathbf{R}^{2}$ & $\mathbf{R}^{2}$ average & S.D. (\%) \\
\hline $\mathbf{3 . 2}$ & -0.0823 & 0.002 & 0.00222 & 0.99 & & 1.7 \\
\hline $\mathbf{1 0 . 6}$ & -0.0383 & 0.0066 & 0.00692 & 0.94 & & 3.4 \\
\hline $\mathbf{1 8 . 4}$ & -0.0334 & 0.00811 & 0.01182 & 0.97 & & 3.3 \\
\hline $\mathbf{4 5 . 6}$ & -0.0226 & 0.013 & 0.03024 & 0.97 & 0.975 & 4.4 \\
\hline $\mathbf{2 6 8 . 0}$ & -0.0202 & 0.132 & 0.1754 & 0.99 & & 3.6 \\
\hline $\mathbf{3 3 2 . 0}$ & -0.0176 & 0.173 & 0.2077 & 0.99 & & 4.1 \\
\hline
\end{tabular}

Table 3: Rate constants and correlation coefficients for the pseudo-second-order model at each of the initial EE2 concentration used.

\begin{tabular}{|c|c|c|c|c|c|c|}
\hline $\mathbf{C}_{\mathbf{0}}(\boldsymbol{\mu M})$ & $\mathbf{K}_{\mathbf{2}} / \mathbf{g ~ m g}^{-1} \mathbf{~ m i n}^{-1}$ & $\mathbf{q}_{\mathrm{e}, \text { calc }} / \mathbf{m g ~ g}^{-1}$ & $\mathbf{q}_{\text {e,exp }} / \mathbf{m g ~ g}^{-1}$ & $\mathbf{R}^{2}$ & $\mathbf{R}^{2}$ average & S.D. (\%) \\
\hline $\mathbf{3 . 2}$ & 3428.4 & 0.00244 & 0.00222 & 0.99 & & 3.2 \\
\hline $\mathbf{1 0 . 6}$ & 2367.4 & 0.00816 & 0.00692 & 0.99 & & 2.7 \\
\hline $\mathbf{1 8 . 4}$ & 1129.4 & 0.01324 & 0.01182 & 0.99 & & 4.1 \\
\hline $\mathbf{4 5 . 6}$ & 288.34 & 0.03155 & 0.03024 & 0.99 & & 1.8 \\
\hline $\mathbf{2 6 8 . 0}$ & 89.72 & 0.1867 & 0.1754 & 0.99 & & 5.3 \\
\hline $\mathbf{3 3 2 . 0}$ & 129 & 0.2325 & 0.2077 & 0.99 & & 5.5 \\
\hline
\end{tabular}

Table 4: $\alpha$ and $\beta$ constants and correlation coefficients for different EE2 concentrations in reference to the SimpleElovich Model.

\begin{tabular}{|c|c|c|c|c|c|}
\hline $\mathbf{C}_{\mathbf{0}}(\boldsymbol{\mu M})$ & $\mathbf{a} / \mathbf{m g ~ g}^{-1} \mathbf{~ m i n}^{-1}$ & $\boldsymbol{\beta} / \mathbf{g ~ m g ~}^{-1}$ & $\mathbf{R}^{2}$ & $\mathbf{R}^{2}$ average & S.D. $(\%)$ \\
\hline $\mathbf{3 . 2}$ & 0.1836 & 0.4932 & 0.9866 & & 2.4 \\
\hline $\mathbf{1 0 . 6}$ & -1.0548 & 1.7415 & 0.9977 & & 1.3 \\
\hline $\mathbf{1 8 . 4}$ & -0.8998 & 2.7678 & 0.9386 & & 6.2 \\
\hline $\mathbf{4 5 . 6}$ & 5.6869 & 4.9535 & 0.9223 & 0.97 & 7.7 \\
\hline $\mathbf{2 6 8 . 0}$ & -15.399 & 36.356 & 0.9842 & & 4.7 \\
\hline $\mathbf{3 3 2 . 0}$ & -40.237 & 45.961 & 0.995 & & 5.5 \\
\hline
\end{tabular}

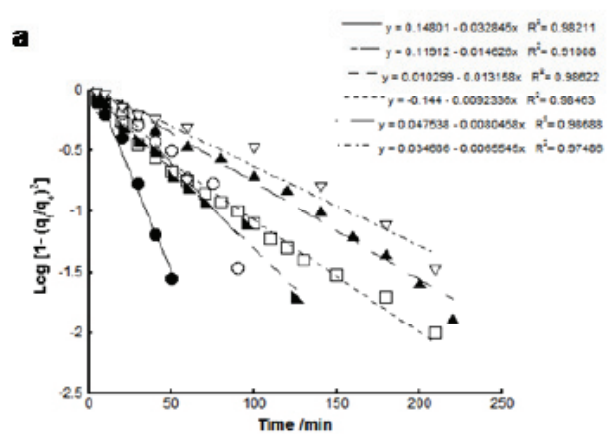

b

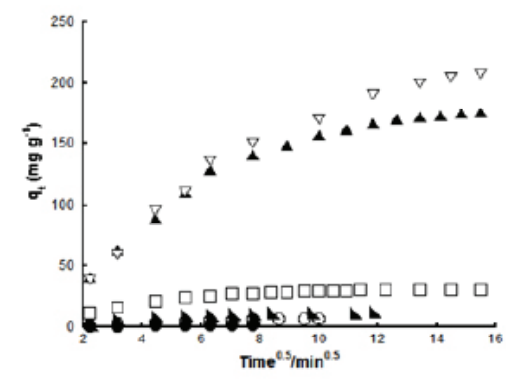

c
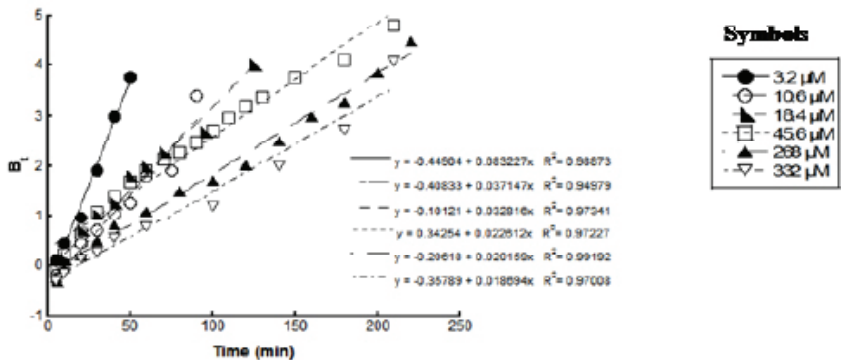

Figure 8: Isothermal adsorption models: a) Dumwald -Wagner model; b) Intraparticle; c) Boyd.

Table 5: Diffusion rate constants calculated on the basis of diffusion model for the different EE2 concentrations used.

\begin{tabular}{|c|c|c|}
\hline $\mathrm{C}_{0}(\mu \mathrm{M})$ & $\mathrm{K}_{\mathrm{D}-\mathrm{w}}$ & $\mathbf{R}^{2}$ \\
\hline 3.2 & 0.0755 & 0.98 \\
\hline $\mathbf{1 0 . 6}$ & 0.0336 & 0.91 \\
\hline $\mathbf{1 8 . 4}$ & 0.031 & 0.98 \\
\hline $\mathbf{4 5 . 6}$ & 0.021 & 0.98 \\
\hline $\mathbf{2 6 8 . 0}$ & 0.018 & 0.99 \\
\hline 332.0 & 0.015 & 0.97 \\
\hline
\end{tabular}

the curves. These two linear portions in the intraparticle model suggest that the adsorption process consists of both surface adsorption and intraparticle diffusion. While the initial linear portion of the plot indicates boundary layer effect, the second linear portion is due to intraparticle diffusion [18]. The intraparticle diffusion rates $\mathrm{K}_{\mathrm{id}}$, calculated from the slope of the second linear portion, are given in table 6 . The values of $\mathrm{C}$, also reported in the table, provide an idea about the thickness of the boundary layer. The larger the intercept, the greater is the boundary layer effect [19]. Increasing of initial EE2 concentration leads to the increase in boundary layer effect for EE2 adsorption. 
Table 6: Parameters obtained from the intraparticle diffusion model for the different EE2 concentration.

\begin{tabular}{|c|c|c|c|}
\hline $\mathbf{C}_{\mathrm{o}}(\boldsymbol{\mu M})$ & $\mathbf{K}_{\mathrm{id}}\left(\mathbf{m g ~ g}^{-1} \mathbf{m i n}^{-0.5}\right)$ & $\mathbf{C}\left(\mathbf{m g ~ g}^{-1}\right)$ & $\mathbf{R}^{2}$ \\
\hline 3.2 & 0.0441 & 1.7881 & 1 \\
\hline 10.6 & 0.3889 & 3.0622 & 0.94 \\
\hline 18.4 & 0.2512 & 8.8929 & 0.98 \\
\hline 45.6 & 0.3803 & 24.936 & 0.86 \\
\hline 268.0 & 4.4109 & 111.05 & 0.94 \\
\hline 332.0 & 7.6624 & 94.114 & 0.97 \\
\hline
\end{tabular}

To characterize what is the actual step involved in the EE2 adsorption process, our data have been analyzed using the Boyd kinetic expression given in equation 18. The calculated $B_{t}$ values have been plotted against time as shown in figure 8c. The linearity of these plots provides useful information to distinguish between external transport and intraparticletransport controlled rates. Since each one of the straight lines does not pass through the origin, it is possible to conclude that film diffusion governs the rate limiting of the process.

\section{Conclusions}

Laboratory studies have been carried out to remove 17- $\alpha$ ethinylestradiol from synthetic aqueous solutions by adsorption onto PAN beads. Significant indications about the adsorption mechanism have been obtained.

Among the four adsorption isotherm models tested, the Freundlich model gave the highest $\mathrm{R}^{2}$ value, i.e. 0.97. The Freundlich and Dubinin-Radushkevich models, also, suggest that neither homogeneous site energies nor limited levels of adsorption are adequate to explain the obtained results. It is reasonable to conclude that, in our case, electrostatic forces play a significant role in the adsorption process.

The pseudo-second-order kinetic equation $\left(\mathrm{R}^{2}=0.99\right)$ has explained the kinetic of the EE2 adsorption rate.

Different adsorption models have been examined to illustrate the diffusion mechanism of $17-\alpha$ ethinylestradiol adsorption. The diffusion rate equations inside particulate of Dumwald-Wagner and intraparticle models have been used to calculate the diffusion rate of EE2 onto PAN beads. Since E values are less than $8 \mathrm{~kJ} / \mathrm{mol}$, the adsorption process has a physical nature. To determine what was the actual rate-controlling step involved in the adsorption process, the adsorption data have further analyzed by the kinetic expression given by Boyd.

In all the model studied the $\mathrm{R}^{2}$ values resulted congruous with the S.D. values.

Adsorption process appears a physical adsorption process, while on the basis of the Pseudo-second-order model adsorption appears to be governed by chemi-adsorption This contradiction is only apparent since the adsorption process could be a mixture of more than one process: physical adsorption, chemical adsorption, and mass balance. In our case, the first and main step is the physical adsorption step as proved by $\mathrm{D}-\mathrm{R}$ model, while the second and rate determined step is the chemical one as proved by the Pseudo-second- order model. The chemical adsorption step raised from the interaction occurred between the charged $\mathrm{LiNO}_{3}$ component in the PAN beads and the charges on the OH groups of EE2.

Our results clarify the molecular mechanisms at the basis of our adsorption process, and, in addition, confirm the useful employment of the PAN beads in removing pollutant, in particular, EE2, from aqueous systems.

\section{Acknowledgments}

We thank the Interuniversity Consortium INBB for supporting Dr. Maurizio Forte and Dr. Luigi Mita with fellowships.

\section{References}

1. Diamanti-Kandarakis E, Bourguignon JP, Giudice LC, et al.(2009) Endocrine disrupting chemicals: an Endocrine Society scientific statement. Endocr Rev; 30(4): 293-342. Link: https://goo.gl/7Q80Nj

2. Silva $C P$, Otero $M$, Esteves V. Processes (2012) for the elimination of estrogenic steroid hormones from water: a review. Environ Pollut; 165: 38-58. Link: https://goo.gl/RxjUll

3. Aris AZ, Shamsuddin AS, Praveena SM. (2014) Occurrence of 17alphaethynylestradiol (EE2) in the environment and effect on exposed biota: a review. Environ Int; 69: 104-19. Link: https://goo.gl/2mYYSt

4. Xu N, Xu YF, Xu S, Li J, Tao HC. (2012) Removal of estrogens in municipal wastewater treatment plants: a Chinese perspective. Environ Pollut; 165 215-24. Link: https://goo.gl/3v9P1z

5. Combalbert S, Hernandez-Raquet G. Occurrence, (2010) fate, and biodegradation of estrogens in sewage and manure. Appl Microbiol Biotechnol; 86(6): 1671-92. Link: https://goo.gl/0aMWiW

6. Gabet V, Miege C, Bados P, Coquery M (2007) Analysis of estrogens in environmental matrices. Trac-Trends in Analytical Chemistry; 26(11): 11131131. Link: https://goo.gl/ADYrFd

7. Atkinson SK, Marlatt VL, Kimpe LE, et al. (2012) The occurrence of steroida estrogens in south-eastern Ontario wastewater treatment plants. Science of the Total Environment; 430: 119-25. Link: https://goo.gl/QAQ3XL

8. Cargouet M, Perdiz D, Mouatassim-Souali A, Tamisier-Karolak S, Levi Y (2004) Assessment of river contamination by estrogenic compounds in Paris area (France). Sci Total Environ; 324(1-3): 55-66. Link: https://goo.gl/DGMJIV

9. Vigano L, Mandich A, Benfenati E, R. BertolottiS. Bottero et al. (2006) Investigating the estrogenic risk along the river Po and its intermediate section. Arch Environ Contam Toxicol; 51(4): 641-651. Link: https://goo.gl/36hMqe

10. Ra JS, Lee SH, Lee J, et al. (2011) Occurrence of estrogenic chemicals in South Korean surface waters and municipal wastewaters. J Environ Monit; 13(1): 101-109. Link: https://goo.gl/c2M6QH

11. Parrott JL, Blunt BR. (2005) Life-cycle exposure of fathead minnows (Pimephales promelas) to an ethinylestradiol concentration below $1 \mathrm{ng} / \mathrm{L}$ reduces egg fertilization success and demasculinizes males. Environ Toxicol; 20(2): 131-141. Link: https://goo.gl/krDVP9

12. Pawlowski S, van Aerle R, Tyler CR, Braunbeck T (2004) Effects of 17alphaethinylestradiol in a fathead minnow (Pimephales promelas) gonadal recrudescence assay. Ecotoxicol Environ Saf; 57(3): 330-345. Link: https://goo.gl/Tt5DDX

13. Hua J, Han J, Wang X, Guo Y, Zhou B (2016). The binary mixtures of megestrol acetate and 17 alpha-ethynylestradiol adversely affect zebrafish reproduction. Environ Pollut; 213: 776-784. Link: https://goo.gl/ZHjtdY 
14. Luzio A, Monteiro SM, Rocha E, Fontainhas-Fernandes AA, Coimbra AM (2016) Development and recovery of histopathological alterations in the gonads of zebrafish (Danio rerio) after single and combined exposure to endocrine disruptors (17alpha-ethinylestradiol and fadrozole). Aquat Toxicol; 175: 90-105. Link: https://goo.gl/eWfXie

15. Armstrong BM, Lazorchak JM, Jensen KM, Haring HJ4, Smith ME4,et al (2016) Reproductive effects in fathead minnows (Pimphales promelas) following a $21 \mathrm{~d}$ exposure to 17alpha-ethinylestradiol. Chemosphere; 144 366-373. Link: https://goo.gl/YS9ol4

16. Kidd KA, Blanchfield PJ, Mills KH, Vince P. Palace *, Robert E. Evans, et al (2007) Collapse of a fish population after exposure to a synthetic estrogen. Proc Natl Acad Sci U S A; 104(21): 8897-901. Link: https://goo.gl/chl5pZ

17. EU. Directive 2013/39/EU of the European Parliament and of the Council, of 12 August 2013, amending Directives 2000/60/EC and 2008/105/EC as regards priority substances in the field of water policy. Off J Eur Union2013. p. 1-17.

18. Secondes MF, Naddeo V, Belgiorno V, Ballesteros F, Jr, (2014) Remova of emerging contaminants by simultaneous application of membrane ultrafiltration, activated carbon adsorption, and ultrasound irradiation. J Hazard Mater; 264: 342-349. Link: https://goo.gl/orLdRu

19. Diano N, Grano V, Fraconte L, P. Caputoa, b, A. Ricupitoc, et al. (2007) Nonisothermal bioreactors in enzymatic remediation of waters polluted by endocrine disruptors: BPA as a model of pollutant. Appl. Catal. B Environ.; 69: 252-61. Link: https://goo.gl/Dhdn6h

20. Georgieva S, Godjevargova T, Portaccio M, Lepore M, Mita D.G (2008) Advantages in using non-isothermal bioreactors in bioremediation of water polluted by phenol by means of immobilized laccase from Rhus vernicifera. J. Mol. Catal. B Enzym.; 55: 177-184. Link: https://goo.gl/YWatgh

21. Mita L, Sica V, Guida M, Marco Guidad, Carla Nicoluccia, Tiziana Grimaldia ,et al. (2010) Employment of immobilised lipase from Candida rugosa for the bioremediation of waters polluted by dimethylphthalate, as a model of endocrine disruptors. J. Mol. Catal. B Enzym.; 62: 133-141. Link: https://goo.gl/zhRYGM

22. Nicolucci C, Rossi S, Menale C, Godjevargova T, Ivanov Y, et al. (2011) Biodegradation of bisphenols with immobilized laccase or tyrosinase on polyacrylonitrile beads. Biodegradation; 22(3): 673-683. Link: https://goo.gl/muLCvL

23. Kumar A.K, Mohan S.V (2012) Removal of natural and synthetic endocrine distrupting estrogens by multi-walled carbon nanotubes (MWCNT) as adsorbent: Kinetic and mechanistic evaluation. Sep. Purif. Technol; 87: 22 30. Link: https://goo.gl/aBPwSP

24. M. Evy Alice Abigail, R. C (2016) Rice husk as a low cost nanosorbent for 2,4-dichlorophenoxyacetic acid removal from aqueous solutions. Ecological Engineering; 92: 97-105. Link: https://goo.gl/gSrt05

25. Aly Z, Graulet A, Scales N, T. H. (2014) Removal of aluminium from aqueous solutions using PAN-based adsorbents: characterisation, kinetics, equilibrium and thermodynamic studies. Environ. Sci. Pollut. Res. Int; 21 : 3972-86. Link: https://goo.gl/4Y2ooH

26. Sun S, Hunag J, C. Z (2011) Polymeric Particles for the Removal of Endocrine Disruptors. Sep. Purif. Rev; 40: 312-337. Link: https://goo.gl/rL1bqp

27. Coelho GF, Goncalves AC, Tarley CRT, Herbert Nacke, et al. (2014) Removal of metal ions $\mathrm{Cd}$ (II), $\mathrm{Pb}$ (II), and $\mathrm{Cr}$ (III) from water by the cashew nut shell Anacardium occidentale L. Ecological Engineering; 73: 514-525. Link: https://goo.gl/cQ9LDi

28. Victor-Ortega M.D, Ochando-Pulido J.M., A. M-F (2016) Thermodynamic and kinetic studies on iron removal by neans of a novel strong-acid cation exchange resin for olive mill effluent reclamation. Ecological Engineering; 86: 53-59. Link: https://goo.gl/40wfoQ

29. Ali RM, Hamad HA, Hussein MM, Malash GF (2016) Potential of using green adsorbent of heavy metal removal from aqueous solutions: Adsorption kinetics, isotherm, thermodynamic, mechanism and economic analysis. Ecological Engineering; 91: 317-32.Link: https://goo.gl/utwJjQ

30. Víctor-Ortega M.D, Ochando-Pulido J.M (2016) Martinez-Ferez A. Phenols removal from industrial effluents through novel polymeric resins: Kinetics and equilibrium studies. Sep. Purif. Technol; 160: 136-44. Link: https://goo.gl/QZ5B6x

31. Víctor-Ortega M.D, Ochando-Pulido J.M, Martinez-Ferez (2015) A Inpacts of integrated strong-acid cation exchange and weak-base anion exchange process for successful removal of saline toxicity from model olive mill wastewater. Ecological Engineering; 77: 18-25. Link: https://goo.gl/9s1fkA

32. Su-Hsia I, Ruey-Shin J (2009) adsorption of phenol and its derivatives fram water using synthetic resins and low-cost natural adsorbents: A review: Jornal Environ. Manag.; 90: 1336-1349. Link: https://goo.gl/OixY1u

33. Menale C, Nicolucci C, Catapane M, U. Bencivengac, D.G. Mita, et al. (2012) Optimization of operational conditions for biodegradation of chlorophenols by laccase-polyacrilonitrile beads system. Journal of Molecular Catalysis B-Enzymatic; 78: 38-44. Link: https://goo.gl/spzXvu

34. Catapane M, Nicolucci C, Menale C, Mita L, Rossi S, Mita DG et al. (2013) Enzymatic removal of estrogenic activity of nonylphenol and octylphenol aqueous solutions by immobilized laccase from Trametes versicolor. Journal of Hazardous Materials; 248: 337-46. Link: https://goo.gl/MQ60ZD

35. Sarkar B, Xi YF, Megharaj M, Naidu R (2011) Orange II adsorption on palygorskites modified with alkyl trimethylammonium and dialkyl dimethylammonium bromide - An isothermal and kinetic study. Applied Clay Science; 51(3): 370-374. Link: https://goo.gl/988nf3

36. Ho YS, McKay G (1999) Pseudo-second order model for sorption processes Process Biochemistry; 34(5): 451-65.Link: https://goo.gl/Z6pWB

37. Bayramoglu G, Altintas B, Arica MY (2009) Adsorption kinetics and thermodynamic parameters of cationic dyes from aqueous solutions by using a new strong cation-exchange resin. Chemical Engineering Journal; 152(2-3): 339-346. Link: https://goo.gl/6Q6Szv

38. Wu FC, Tseng RL, Juang RS (2009) Characteristics of Elovich equation used for the analysis of adsorption kinetics in dye-chitosan systems. Chemical Engineering Journal; 150(2-3): 366-73. Link: https://goo.gl/a2KV4O

39. Wang $\mathrm{H}$, Jindong $\mathrm{C}$, Zhai Z, Jindong C (2004) Study on thermodynamics and kinetics of adsorption of p-toluidine from aqueous solution by hypercrosslinked polymeric adsorbents. Environ. Chem; 23: 192-6. Link https://goo.gl/irHWBp

40. Onal Y (2006) Kinetics of adsorption of dyes from aqueous solution using activated carbon prepared from waste apricot. Journal of Hazardous Materials; 137(3): 1719-28. Link: https://goo.gl/ILyTZh

41. Boyd G.E., Adamson W, L.S. M (1947). The exchange adsorption of ions from aqueous solutions by organic zeolites; kinetics. J. Am. Chem. Soc. 69: 2836 48. Link: https://goo.gl/ell3y6

42. Smith B (1999) Infrared spectral interpretation, CRC - Press. Link: https://goo.gl/VNLNDI

43. Mary D, Freeda M, Jayam G. (2015) Solution growth and studies of undoped and lithium nitrate added glycine sodium nitrate single crystals. J Chem Pharm Res; 7: 242-246. Link: https://goo.gl/w5q2Hj

Copyright: (c) 2017 Mita L, et al. This is an open-access article distributed under the terms of the Creative Commons Attribution License, which permits unrestricted use distribution, and reproduction in any medium, provided the original author and source are credited.

Citation: Mita L, Forte M, Rossi A, Adamo C, Rossi S, et al. (2017) Removal of 17-a Ethinylestradiol from Water Systems by Adsorption on Polyacrylonitrile Beads: Isotherm and Kinetics Studies. Ann Environ Sci Toxicol 2(1): 048-058. DOI: https://dx.doi.org/10.17352/aest.000012 